\title{
Regional mobility and unemployment transitions in the UK and Spain*
}

\author{
Joanne Lindley Richard Upward Peter Wright ${ }^{\dagger}$ \\ Leverhulme Centre for Research on Globalisation \\ and Economic Policy \\ University of Nottingham
}

October 4, 2002

\begin{abstract}
If the distribution of industrial employment is uneven across regions, changes in patterns of production will require the reallocation of labour across regions as well as industries. In this paper we consider this aspect of the adjustment process. Specifically, we compare the geographical mobility of the workforce in the UK and Spain, and examine the extent to which differences in mobility explain differences in the probability of exiting unemployment between the two countries.
\end{abstract}

Keywords: unemployment, mobility, regional migration

JEL codes: J61, J64

${ }^{*}$ Financial assistance from the ESRC under Project Grant R000221779 and from The Leverhulme Trust under Programme Grant F114/BF is gratefully acknowledged.

${ }^{\dagger}$ Corresponding author: peter.wright@nottingham.ac.uk 


\section{Introduction}

Figure 1 illustrates the unemployment rate in the UK and Spain over the last 30 years. In the early 1970s unemployment rates were approximately equal. Since the mid-1980s the Spanish unemployment rate has been consistently twice as large as that in the UK, with both countries experiencing a closely synchronized cyclical pattern.

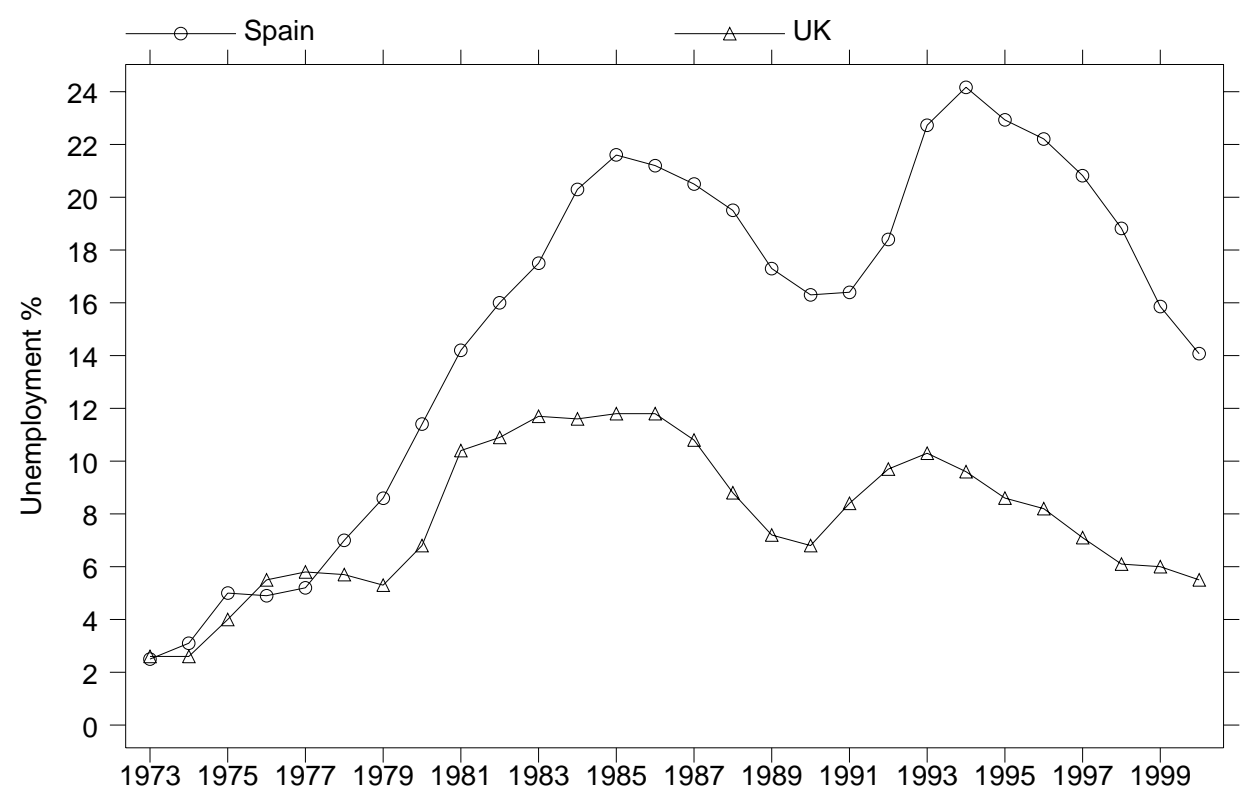

Figure 1: UK and Spanish ILO unemployment 1973-2000

Numerous authors have documented and attempted to explain these patterns. If there is a consensus, it is that a combination of adverse shocks and differences in labour market institutions across countries have caused both the general increase and the divergence of unemployment rates across OECD countries. See, for example, Blanchard \& Wolfers (2000). The most commonly-cited institutional features are unemployment benefit systems, employment protection legislation, union power and wage-setting co-ordination: see Tables 4 and 5 in Nickell (1997) for an illustration.

An additional feature of both Spanish and UK labour markets which has attracted attention recently is the level of inter-regional migration. In both countries it has been suggested that the relative immobility of labour across regions has contributed to increases in the equilibrium level of unemployment. In the 
UK, it has been suggested that the structure of housing tenure has restricted the geographical mobility of workers (Hughes \& McCormick 1981, Cameron \& Muellbauer 1998, Henley 1998, Gardner, Pierre \& Oswald 2001). In Spain, it has frequently been argued that the level of labour mobility is "too low" and that this has led to higher equilibrium unemployment rates (Bentolila \& Blanchard 1990). Labour mobility between regions in Spain appeared to fall between the 1960s and the 1980s (Bentolila 1997), while mobility within regions increased (Bover \& Arellano 2001).

The great majority of the empirical literature on regional migration analyses the determinants of migration. There are essentially two strands of a large literature. The first analyses the aggregate determinants of net migration such as differential unemployment and wage rates (e.g. Cameron \& Muellbauer 1998). The second uses micro-level data to analyse the determinants of the individual probability of migration (e.g. Pissarides \& Wadsworth 1989, Antolin \& Bover 1997), or equivalently aggregate gross migration rates (Jackman \& Savouri 1992).

This paper differs in that we consider how differences in geographical mobility between the UK and Spain influence transition probabilities between labour market states, and hence the equilibrium level of employment and unemployment. We use comparable individual-level data for each country and compare the transition probabilities between labour market states, and examine how inter-regional migration impacts on these probabilities. We use individual-level data because, as noted by Bover, Barćia-Perea \& Portugal (2000) "... aggregate data masks interactions between individual and institutional characteristics, giving rise to biases or the cancellation of interesting effects." Although there are many studies of migration and unemployment transitions which use individual-level data for the UK and Spain, none, as far as we are aware, make direct comparisons between the two countries using comparable data and econometric methods.

The paper is structured as follows. In Section 2 we outline a framework for analysing flows of labour regions. In Section 3 we describe the econometric methodology we use to estimate the relationship between regional mobility and unemployment transitions. In Section 4 we provide some descriptive evidence, and our econometric results are reported in Section 5. Section 6 concludes. 


\section{Job search and geographical mobility}

The processes of job search and geographical mobility are not easy to disentangle. For example, individuals may search over a wide geographical area without changing location, and then move residence once a job has been found. Alternatively, if the costs of job search increase with distance, individuals may choose to relocate before they find work provided that the expected return to searching is greater in the new location. Gregg, Machin \& Manning (2001) argue that the relationship between economic state and mobility is plagued by simultaneity. Those who are more willing to move region are more likely to find a job, while those search for work more intensively are more likely to move region.

The standard economic model of migration (Sjaastad (1962) is an early example) posits that migration occurs when the discounted stream of future earnings in the new location outweighs the costs of moving. In this framework, migrants respond to differences in unemployment rates or average earnings between regions and hence migration serves to equalise these differences over time. As noted by Jackman \& Savouri (1992), however, this approach does not help to explain the large observed flows both into and out of high unemployment or low-wage regions.

Following Jackman \& Savouri, we prefer to view inter-regional migration as the outcome of a search process: migration occurs when a job-seeker from one region finds a match with a vacancy from another region. In this framework job-seekers do not generally move to other regions in order to search for work. This is supported by various pieces of empirical evidence. Böheim \& Taylor (1999) show that only $8.6 \%$ of those who move residence in the UK in the 1990s for job-related reasons did so to search for work. Gregg et al. (2001) also argue that moving region is more difficult for those who do not have a job, and they provide evidence that those who move region and find work generally find work before moving. 


\subsection{The hiring function}

The basic concept we use to try and understand the relationship between migration and unemployment transitions is the hiring (or matching) function. ${ }^{1}$ We follow the framework of Jackman \& Savouri (1992). The total number of hires per period is a function of the stocks of unemployed $U$ (or more generally, job-seekers) and vacancies $V$ in the economy:

$$
h=h(U, V) h_{U}, h_{V}>0 .
$$

Now suppose we arbitrarily split this economy into regions. With perfect mobility between regions, exactly the same number of matches will occur, but some of these matches will be between job-seekers and vacancies in different regions, leading to migration. The number of individuals who migrate from region $i$ to region $j, m_{i j}$, is given by the number of job-seekers from region $i$ who find a job in region $j$,

$$
m_{i j}=h u_{i} v_{j}
$$

where $u_{i}$ is the share of unemployment in region $i$ and $v_{j}$ is the share of vacancies in region $j$. Total out-migration from region $i$ is

$$
m_{i}^{\text {out }}=\sum_{j \notin i} h u_{i} v_{j}=h u_{i}\left(1-v_{i}\right)
$$

and total in-migration to region $i$ is

$$
m_{i}^{\text {in }}=\sum_{j \notin i} h u_{j} v_{i}=h\left(1-u_{i}\right) v_{i} .
$$

Net migration into region $i$ is therefore

$$
m_{i}^{\text {in }}-m_{i}^{\text {out }}=h\left(v_{i}-u_{i}\right)
$$

So, for example, net migration will be positive if a region has a higher share of vacancies than unemployed. In the extreme case where one region has all the vacancies $\left(v_{i}=1\right)$ and none of the job-seekers $\left(u_{i}=0\right)$ then net migration is simply $h$, the total number of hires.

The total level of migration is given by

$$
m=\sum_{i} m_{i}^{\mathrm{in}}=h\left(1-\sum_{i} u_{i} v_{i}\right)
$$

\footnotetext{
${ }^{1}$ For a detailed description of this framework, see Mortensen (1986) and Pissarides (2000).
} 
where the term $1-\sum u_{i} v_{i}$ is an index of mismatch. In the extreme case where region 1 has all the vacancies and region 2 has all the job-seekers, this index will be equal to zero, and total migration is equal to total hires. If one region has all the vacancies and all the job-seekers, this index is 0 and no migration occurs.

Now suppose that the costs of migration are such that moving region is impossible. We now have a number of separate regions $i$ with hires $h_{i}=h\left(U_{i}, V_{i}\right)$ in each region. Under constant returns to scale, ${ }^{2}$ the number of matches will be exactly the same as with a single integrated economy, but only if there is no mismatch in the proportions $u_{i}$ and $v_{i}$. Splitting the labour market into regions has no effect on equilibrium unemployment if labour market tightness (the ratio $\left.\theta_{i}=V_{i} / U_{i}\right)$ is equal across regions. If regions differ in $\theta_{i}$ then the lack of geographical mobility will cause an increase in the equilibrium unemployment rate because the number of matches decrease.

This model suggests that the total amount of migration depends on the total number of job hires in the economy. As shown by Jackman \& Savouri (Figure 3 ) the hiring rate and the migration rate were closely correlated in the UK over the period 1971-1983. In Figure 2 we plot an estimate of $h$ and $m$ for the UK and Spain over the period of our data. ${ }^{3} h$ is the rate at which the unemployed find jobs, and $m$ is the rate at which the unemployed move region. Although estimates of $m$ are rather imprecise, especially in Spain, there does appear to be quite a close correlation between the hiring and the migration rate. Note however that the migration rate in Spain (right hand scale) is far lower than that in the UK.

\subsection{The individual transition out of unemployment}

From the aggregate hiring function, Equation (1), it follows that the probability of an individual job-seeker matching with a vacancy is $h / U$. We now need to consider how $h / U$ varies across individuals in terms of their willingness to migrate. We can decompose Equation (1) into two components: the number

\footnotetext{
${ }^{2}$ It is usually assumed that $h$ in Equation (1) exhibits constant returns to scale, and much empirical evidence supports this.

${ }^{3}$ The data sources are described in Section 4 .
} 

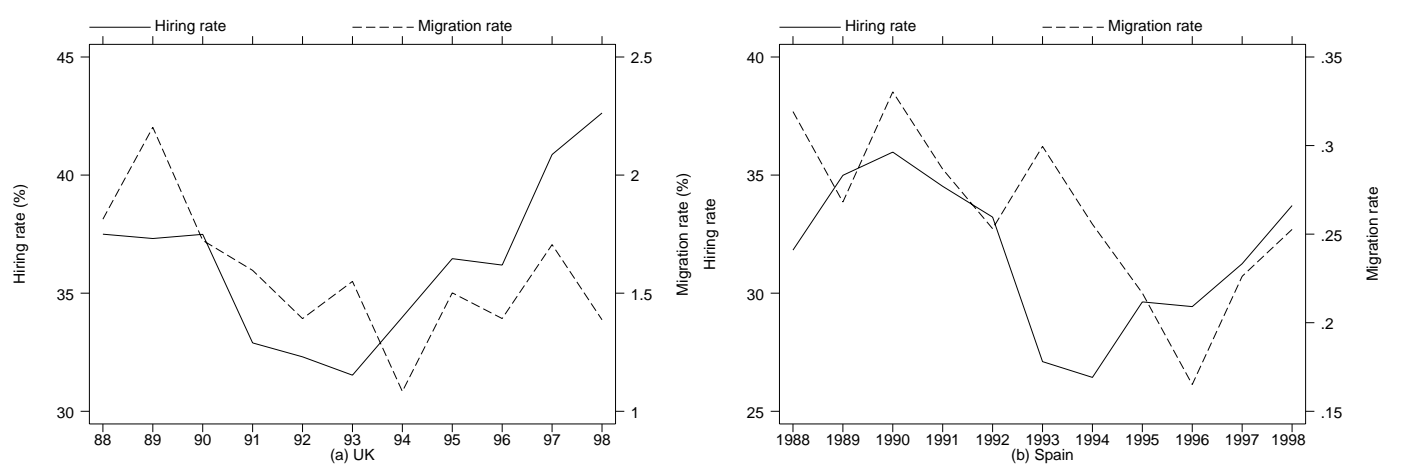

Figure 2: Hiring rates and migration rates amongst the unemployed

of "contacts" between the job seeker and vacancies, and the probability that each contact results in a hire.

$$
h(U, V)=\mu(U, V) \lambda(U, V)
$$

where $\mu$ is the matching probability and $\lambda$ is the rate at which job-seekers and vacancies contact each other. We now assume that individual job-seekers vary in the number of contacts $\lambda$ which occur, by introducing a term $c_{i}$ which refers to search effectiveness of individual $i$ : an individual with a higher value of $c_{i}$ will receive more job offers (or contacts). Search effectiveness is a function of, amongst other things, the willingness to move region, because an individual who searches for jobs in the whole economy will have a higher contact rate than one who only searches in their local region: search effectiveness, and the probability of exiting unemployment, depends on the job-seeker's willingness to move region. The individual transition rate out of unemployment can therefore be written as

$$
\operatorname{Pr}\left(h_{i}\right)=\mu_{i} \lambda_{i}\left(c_{i}, U, V\right),
$$

where $c_{i}$ is a function of willingness to move region.

We therefore need to consider how willingness to move region varies across individuals and what determines whether individuals search for jobs in other regions. As noted, the traditional economic view of migration compares the costs and benefits of residence in each region, where benefits are defined in terms of the expected value of employment. This in turn is a function of the average wage and the employment rate in each region. In our framework, however, the average regional wage and employment rate are relatively unimportant, since job-seekers are deciding whether to accept or reject a particular 
job offer from a particular region. If the net present value of that job offer exceeds the value of staying in the current region, an individual will choose to move. (Regional average wages and employment rates may however affect the number of potentially acceptable job offers from a region.)

Instead, we assume that individuals differ in their propensity to move region, for two reasons. First, the cost of acquiring information about job opportunities in other regions may vary across individuals. Gregg et al. (2001) suggest that in the UK some vacancies (those offering unskilled work) are not advertised nationally. An unskilled worker in one region may therefore find it difficult to acquire information about job opportunities in other regions. The second reason why the propensity to move region varies across individuals is due to differences in the fixed cost of migration. If the costs of moving are high enough, then the expected return to search in another region may be negative. The costs of moving will in turn be a function of:

- Housing tenure. It has often been suggested in the UK literature that those in private rented accommodation face lower mobility costs than either those who are buying their houses (e.g. Oswald 1996) or those who rent in the public sector (e.g. Hughes \& McCormick 1981).

- Partner's economic status. Since the decision to move usually affects the whole household, we would expect that those whose partners are currently in employment in one region will be less mobile between regions than those who are single, since any regional migration will potentially involve the partner having to search for new employment.

- Child care. Families with children might be expected to be less mobile, and this might vary with the age of the children.

- Psychological costs, such as family ties.

- Credit constraints. As noted by Gregg et al. (2001) the unemployed in particular might find it difficult to move region if they face credit constraints.

This framework suggests that individuals vary in the costs they face when moving region, as a result of the factors listed above. Those who face low 
costs are more likely to search for jobs in regions other than their region of residence, and will therefore tend on average to receive higher numbers of job offers. This provides us with a potential method for estimating the relationship between inter-region migration and unemployment transitions, which we outline in Section 3.

The data we use do not allow us to identify contacts or whether a particular contact between a job-seeker and a vacancy results in a match. We cannot therefore test directly whether differences in the costs of migration affect $\lambda$ or $\mu$. Instead, we use information on the labour market status for each individual at 12 -month intervals. This allows us to estimate the transition rates between labour market states. In other words, we can estimate a reduced form of Equation (2) if we can identify factors which affect $c_{i}$ across individuals.

\section{Econometric methods}

In measuring the impact of migration propensity on the likelihood of exiting unemployment a number of econometric issues arise. Firstly the dependent variables in both the migration and the unemployment exit equations are binary. This necessitates the use of limited dependent variable methods. The underlying propensity to migrate from one region to another between $t$ and $t+1$ is modelled as a linear function of individual and household characteristics, and the proportion of unemployed and vacancies in that region.

$$
\mathbf{y}_{1}^{*}=\mathbf{X}_{1} \boldsymbol{\beta}_{1}+\mathbf{u}_{1}
$$

The propensity $\mathbf{y}_{1}^{*}$ is unobserved, and so the observable indicator variable $\mathbf{m}$ is defined as

$$
m_{i}= \begin{cases}1 & \text { if } y_{1 i}^{*}>0 \\ 0 & \text { otherwise }\end{cases}
$$

That is, an individual is observed to move region $\left(m_{i}=1\right)$ if their underlying propensity is sufficiently high.

In this model $\mathbf{X}_{1}$ includes any characteristics which affect the cost of moving from one region to another, but which do not affect the arrival rate of job offers from the origin region. For example, having a working partner will almost 
certainly increase the costs of mobility. If having a working partner does not affect the arrival rate of job offers from the origin region then individuals with working partners experience lower transition rates out of employment because they are unable to move region. In this sense $\mathbf{X}_{1}$ includes variables which identify the effect of regional mobility on unemployment outflows.

$\mathbf{X}_{1}$ also includes those characteristics which affect the proportion of job offers received from the home region. For example, higher-educated workers may receive a greater proportion of job-offers from other regions, increasing the probability of moving. Note that if a characteristic increases the offer arrival rate equally in all regions, it will not affect the probability of migration. Note that many variables which affect the proportion of job offers received from the origin region will also affect the total number of job offers received, and so will also be included in the unemployment transition model.

Finally, $\mathbf{X}_{1}$ includes the terms $u_{r, t-1}$ and $v_{r, t-1}$, the relative unemployment and vacancy rates in the region of residence at time $t-1$. A high value of $u_{r, t-1}$ should increase migration because it increases the proportion of job offers received from outside regions. A high value of $v_{r, t-1}$ should reduce migration because it reduces the proportion of job offers from outside regions.

We model $\mathbf{y}_{1}^{*}$ using a standard Probit estimator (Greene 2000, p.812) and from this predict the migration propensity of each individual. This is then used as a regressor in Equation (4). The use of a generated variable in this way produces consistent estimates provided $\hat{\mathbf{y}}_{1}^{*}$ is uncorrelated with $\mathbf{u}_{2}$. However an appropriate correction is needed to the variance-covariance matrix to account for the sampling variation in the first stage parameters (Wooldridge 2002, p.116).

The propensity to exit unemployment is given by:

$$
\mathbf{y}_{2}^{*}=\hat{\mathbf{y}}_{1}^{*} \gamma+\mathbf{X}_{2} \boldsymbol{\beta}_{2}+\mathbf{u}_{2}
$$

As before, we do not observe $\mathbf{y}_{2}^{*}$, and therefore the observable dummy variable indicating whether an individual exits unemployment, $\mathbf{j}$, is defined as

$$
j_{i}= \begin{cases}1 & \text { if } y_{2 i}^{*}>0 \\ 0 & \text { otherwise }\end{cases}
$$


Thus an individual is observed to exit unemployment if their propensity is sufficiently high. Note that $\mathbf{y}_{2}^{*}$ is a function of $\hat{\mathbf{y}}_{1}^{*}$, the migration propensity from Equation (3). The coefficient on $\hat{\mathbf{y}}_{1}^{*}$ is therefore an estimate of the effect of migration propensity on the probability of exiting unemployment.

In Equation (4), the explanatory variables $\mathbf{X}_{2}$ include those characteristics which affect both $\lambda$ and $\mu$ in Equation (2). As noted, this will include many (but not all) of the variables which entered in $\mathbf{X}_{1}$. Of course, these variables may have a different impact on $\mathbf{y}_{2}^{*}$ than they had on $\mathbf{y}_{1}^{*}$. Crucially, $\mathbf{X}_{2}$ excludes those variables in $\mathbf{X}_{1}$ which are assumed to affect the costs of migration but which do not affect search intensity directly.

\section{Data and descriptive statistics}

\subsection{The data}

The data we use are taken from the UK Labour Force Survey (LFS) and the Spanish Active Population Survey (APS) for the years 1987-1998. These surveys are conducted under a similar methodology and offer generally comparable information for each country (Office for National Statistics 2002, Instituto Nacional de Estadística 2002). The data also offer large sample sizes — approximately 60,000 households are interviewed each year. This is important, because as we will show, inter-regional migration is actually a rare event, particularly in Spain. In order to estimate Equations (3) and (4) successfully we therefore need large samples. We focus on the years covering roughly the last decade as these are the only years where the relevant information is available in both surveys.

In every year of the survey, individuals are asked about their current labour force status (working, unemployed, inactive) and their region of residence. Crucially, individuals are also asked about their labour force status and region 12 months previously. Thus, although the survey is not a panel in the sense that the same individuals are interviewed more than once, it is possible to measure transitions between labour market states and movements between regions over a 12-month period. The data also contain numerous other individual charac- 
teristics, including age, sex and educational qualifications. Because the data come from household surveys, it is straightforward to link individuals who live in the same household to construct measures of household structure, including marital status, whether an individual's partner is in employment, number and age of children and so on.

Table 1 summarises the sample size we use in all the descriptive statistics and the econometric analysis. We use only on those individuals of working age who have a complete set of explanatory variables. This still leaves us with a total sample of around 1 million individuals for each country.

\begin{tabular}{lrr}
\hline & UK LFS & Spanish APS \\
& & \\
(a) Total sample size & 1742764 & 2142549 \\
(b) Of working age & 1026447 & 1347736 \\
(c) Of working age with no missing covariates & 963321 & 1115307 \\
\hline
\end{tabular}

Table 1: Sample size

\subsection{Regional definitions}

A practical issue is the appropriate definition of a "region". Ideally, we would want to define a region separately for each household as the area within which it is possible to start a new job without incurring any costs of migration. However, the geographical information available in the data is far more limited. The most disaggregated definitions of region available consistently across the sample period are listed in Table 2, together with their area and population. These correspond to Administrative Regions in each country.

As is clear, the regional definitions we use vary considerably both across regions and across countries, and nor do they correspond closely to our preferred definition. In particular, the Spanish regions are much larger on average, although there is greater variation in area and population within Spain. If the costs of moving region were related to distance, this might reduce the level of migration in Spain relative to the UK. However, in the model the probability of moving region is just the probability of receiving an acceptable job offer from another region. If the costs of moving are primarily a fixed cost above a certain distance, then this difference in average region size would not matter 


\begin{tabular}{|c|c|c|c|c|c|}
\hline \multirow{2}{*}{$U K$} & \multirow[b]{2}{*}{$\begin{array}{c}\text { Pop. } \\
\text { (000s) }\end{array}$} & \multirow[b]{2}{*}{$\begin{array}{c}\text { Area } \\
\left(\mathrm{km}^{2}\right)\end{array}$} & \multicolumn{3}{|c|}{ Spain } \\
\hline & & & & $\begin{array}{l}\text { Pop. } \\
\text { (000s) }\end{array}$ & $\begin{array}{c}\text { Area } \\
\left(\mathrm{km}^{2}\right)\end{array}$ \\
\hline North East & 2577 & 8592 & Galicia & 2733 & 29575 \\
\hline Yorkshire \& Humberside & 5058 & 15411 & Cantabria & 538 & 5321 \\
\hline North West & 6894 & 14165 & Asturias & 1075 & 10604 \\
\hline East Midlands & 4208 & 15627 & País Vasco & 2101 & 7234 \\
\hline West Midlands & 5335 & 13004 & Navarra & 556 & 10391 \\
\hline East & 4975 & 19120 & Rioja & 270 & 5045 \\
\hline South East & 12835 & 20676 & Aragón & 1200 & 47720 \\
\hline South West & 8115 & 23829 & Madrid & 5372 & 8028 \\
\hline Wales & 2946 & 20779 & Castilla y León & 2479 & 94224 \\
\hline Scotland & 5115 & 78133 & Castilla la Mancha & 1755 & 79461 \\
\hline \multirow[t]{7}{*}{ Northern Ireland } & 1698 & 13576 & Extremedura & 1073 & 41634 \\
\hline & & & Cataluña & 6361 & 32113 \\
\hline & & & Valencia & 4203 & 23255 \\
\hline & & & Balears & 879 & 4992 \\
\hline & & & Andalucia & 7404 & 87595 \\
\hline & & & Murcia & 1190 & 11314 \\
\hline & & & Canarias & 1781 & 7492 \\
\hline
\end{tabular}

Table 2: Regional definitions

so much. Nevertheless, we should be aware that the regional definitions we are forced to use are only rough approximations to the theoretical ideal.

\subsection{Regional mobility}

In Table 3 we show the proportion of the sample who report living in a different region to that 12 months previously. In the UK individuals are also asked if they are living at a different address than 12 months previously. The difference between columns (1) and (2) therefore gives an estimate of intra-regional migration. Information on changes of address is not available in the Spanish data, but individuals are asked if they are living in a different municipality than 12 months previously. The difference between columns (3) and (4) therefore gives another estimate of intra-regional mobility, but only for those who move municipality.

Inter-regional migration rates in the UK are about six times greater on average than in Spain. Even so, rates in the UK are probably not that high by international standards. Greenwood (1997, Table 2) reports rates of $6 \%$ per year for the US, and $2 \%$ per year for Japan and Ireland. Even allowing for 


\begin{tabular}{lcccc}
\hline & \multicolumn{2}{c}{ UK } & \multicolumn{2}{c}{ Spain } \\
& moving & \% moving & \% moving & \% moving \\
region & address & region & municipality \\
1988 & 1.72 & 11.70 & 0.32 & 0.59 \\
1989 & 1.89 & 10.89 & 0.30 & 0.64 \\
1990 & 1.52 & 9.23 & 0.29 & 0.55 \\
1991 & 1.48 & 9.34 & 0.29 & 0.60 \\
1992 & 1.19 & 9.32 & 0.25 & 0.62 \\
1993 & 1.25 & 9.33 & 0.22 & 0.58 \\
1994 & 1.21 & 9.93 & 0.21 & 0.55 \\
1995 & 1.30 & 10.26 & 0.21 & 0.58 \\
1996 & 1.38 & 10.14 & 0.18 & 0.52 \\
1997 & 1.64 & 11.08 & 0.19 & 0.51 \\
1998 & 1.51 & 10.84 & 0.18 & 0.51 \\
& & & & 0.56 \\
\hline
\end{tabular}

Table 3: Regional mobility by year (\%)

large differences in the physical size of regions across countries, there appears to be considerable variation in inter-regional migration.

The cyclical pattern of migration is also very different. In the UK migration is pro-cyclical and follows the hiring rate. In Spain, in complete contrast, the inter-region migration rate has consistently fallen over this sample period, even though the cyclical patterns of the two economies have been quite similar, as shown in Figure 1. It is also interesting to note that the migration patterns of the unemployed (Figure 2) are far more cyclical in Spain than the migration patterns of the population as a whole.

\subsection{Labour market transitions}

Table 4 shows the transition rates between labour market states for the UK and Spain over the sample period. $J$ denotes "in employment", $U$ denotes "unemployed and actively seeking work" and $N$ is a catch-all category for "inactive". Thus the column headed $U \rightarrow J$ shows the percentage of those in unemployment 12 months previously who are now in employment. In 1988 in the UK, for example, our estimate of the unemployment to employment transition rate is $36.13 \%$. In contrast to the basic model, which assumes that only the unemployed are actively seeking work, a large number of hires take place 
as the result of job-to-job movements. Column (1) of Table 4 therefore reports the percentage of those in employment 12 months previously who changed employer.

\begin{tabular}{|c|c|c|c|c|c|c|c|}
\hline \multirow[t]{2}{*}{ (a) UK } & \multirow[b]{2}{*}{$J \rightarrow J^{\mathrm{a}}$} & \multirow[b]{2}{*}{$J \rightarrow U$} & \multirow[b]{2}{*}{$J \rightarrow N$} & \multirow[b]{2}{*}{$U \rightarrow J$} & \multirow[b]{2}{*}{$U \rightarrow N$} & \multirow[b]{2}{*}{$N \rightarrow J$} & \multirow[b]{2}{*}{$N \rightarrow U$} \\
\hline & & & & & & & \\
\hline 1988 & 10.88 & 2.99 & 2.82 & 37.50 & 17.97 & 17.06 & 6.58 \\
\hline 1990 & 11.56 & 3.06 & 2.87 & 37.49 & 17.80 & 16.86 & 6.30 \\
\hline 1992 & 7.88 & 4.46 & 3.71 & 32.31 & 17.15 & 15.85 & 5.36 \\
\hline 1994 & 7.58 & 3.15 & 3.40 & 33.99 & 16.58 & 15.84 & 5.59 \\
\hline 1996 & 9.12 & 2.73 & 3.24 & 36.19 & 17.29 & 16.09 & 5.57 \\
\hline 1998 & 10.23 & 2.03 & 3.17 & 42.63 & 16.70 & 17.13 & 4.97 \\
\hline Total & 9.48 & 3.17 & 3.20 & 35.92 & 17.13 & 16.27 & 5.76 \\
\hline \multirow[t]{2}{*}{ (b) Spain } & & & & & & & \\
\hline & $J \rightarrow J^{\mathrm{a}}$ & $J \rightarrow U$ & $J \rightarrow N$ & $U \rightarrow J$ & $U \rightarrow N$ & $N \rightarrow J$ & $N \rightarrow U$ \\
\hline 1988 & 6.51 & 4.06 & 2.59 & 31.82 & 4.36 & 5.49 & 5.28 \\
\hline 1990 & 10.46 & 4.35 & 2.59 & 35.97 & 5.82 & 6.20 & 4.01 \\
\hline 1992 & 14.96 & 5.98 & 3.80 & 33.22 & 8.92 & 6.42 & 5.48 \\
\hline 1994 & 16.10 & 6.88 & 3.44 & 26.43 & 6.69 & 4.80 & 6.29 \\
\hline 1996 & 16.79 & 5.88 & 3.10 & 29.43 & 7.70 & 5.09 & 5.85 \\
\hline 1998 & 17.22 & 4.49 & 2.88 & 33.71 & 8.18 & 5.67 & 6.05 \\
\hline Total & 13.63 & 5.37 & 3.03 & 31.43 & 6.85 & 5.54 & 5.31 \\
\hline
\end{tabular}

${ }^{\text {a }}$ Denotes changes of employer.

Table 4: Employment transitions by year $(\%)$

In the econometric results (Section 5) we concentrate on transitions out of unemployment into employment. We do this partly for simplicity but also because evidence suggests that it is this rate which is the most important factor in determining the equilibrium level of employment. As noted by Layard, Nickell \& Jackman (1991, p.225), in most countries it is the duration of unemployment spells (the inverse of the transition rate from $U$ to $J$ ) which is the key determinant of the unemployment rate.

Column (2) of Table 4 shows that the inflow rate to unemployment from jobs is higher in Spain, while Column (4) shows that the outflow rate from unemployment to Jobs is lower. Both of these are consistent with the higher unemployment rate in Spain over the sample period. As a crude approximation, the steady-state unemployment rate is given by $l /(l+h)$ where $l$ is 
the firing rate and $h$ is the hiring rate. The sample means from Table 4 are consistent with unemployment rates of $8 \%$ in the UK and $14 \%$ in Spain.

However, it would not be correct to characterise the Spanish labour market as unambiguously less "flexible" than the UK one, partly because job-to-job transition rates appear considerably higher in Spain, and in fact have increased noticeably over the sample period. Although we are not convinced that the job-to-job transitions are strictly comparable across countries, the increase in Spanish rate across the sample period is nevertheless dramatic.

A final noteworthy difference between the two countries concerns transitions into and out of "inactivity", which are far higher in the UK (Columns (5) and (6)). This suggests to us that this state is being used far more as a route to employment in the UK than it is in Spain. Transitions from unemployment to inactivity and transitions from inactivity to jobs are some three times higher in the UK.

\subsection{Simple tests of the model}

Our model of regional mobility has a number of simple testable implications. First, the theory equates regional mobility with job-seeking. This would imply in its simplest form that only those seeking jobs at $t-1$ move region. It also seems reasonable to suppose that the intensity of job-seeking varies with employment status, and so Table 5 reports the migration rate for each employment status 12 months prior to the survey.

\begin{tabular}{ccccccc}
\hline & UK & & & \multicolumn{3}{c}{ Spain } \\
$J$ & $U$ & $N$ & $J$ & $U$ & $N$ \\
& & & & & \\
1.22 & 1.57 & 2.19 & 0.24 & 0.26 & 0.23 \\
\hline
\end{tabular}

Table 5: \% of each employment status who migrate

In Spain, migration rates are highest for the unemployed, and lowest for those reported to be inactive. Although differences between the three groups are small, this is consistent with the notion that the unemployed are more actively seeking work. In contrast, in the UK those with the highest migration rates 
are actually those reported to be inactive. This may be partly be due to the fact that in the UK those who are inactive are actually often seeking work (as reported in Table 4), but it also shows that migration is not simply an outcome of job search.

A second implication of our model is that individuals will only move region if they have a job to go to. Migrants who are unemployed at $t-1$ (12 months before the survey) should generally be in employment at $t$, less those who lose their job in the interim. A weaker test would be to see whether transition rates out of unemployment are higher for migrants than non-migrants. To examine this, Table 6 reports the rate at which migrants and non-migrants move between each of the three labour market states.

\begin{tabular}{|c|c|c|c|c|c|c|c|c|}
\hline \multicolumn{9}{|c|}{ (a) UK } \\
\hline & \multicolumn{4}{|c|}{ Non-migrants } & \multicolumn{4}{|c|}{ Migrants } \\
\hline & $J$ (same) & $J$ (new) & $U$ & $N$ & $J$ (same) & $J$ (new) & $U$ & $N$ \\
\hline$J$ & 84.66 & 9.14 & 3.10 & 3.10 & 43.34 & 36.85 & 8.88 & 10.93 \\
\hline$U$ & & 35.73 & 47.15 & 17.12 & & 47.35 & 34.99 & 17.66 \\
\hline$N$ & & 15.82 & 5.69 & 78.49 & & 36.09 & 8.77 & 55.14 \\
\hline \multicolumn{9}{|c|}{ (b) Spain } \\
\hline & \multicolumn{4}{|c|}{ Non-migrants } & \multicolumn{4}{|c|}{ Migrants } \\
\hline & $J$ (same) & $J$ (new) & $U$ & $N$ & $J$ (same) & $J$ (new) & $U$ & $N$ \\
\hline$J$ & 78.08 & 13.58 & 5.32 & 3.02 & 33.22 & 33.56 & 25.43 & 7.79 \\
\hline$U$ & & 31.38 & 61.77 & 6.85 & & 52.48 & 40.35 & 7.18 \\
\hline$N$ & & 5.51 & 5.29 & 89.20 & & 20.17 & 14.18 & 65.65 \\
\hline
\end{tabular}

Table 6: Employment transitions by migration status

Table 6 shows that in both countries migrants have substantially higher exit rates from unemployment than non-migrants. In the UK, $48 \%$ of migrants who were unemployed at $t-1$ are in employment at $t$, compared to $36 \%$ of nonmigrants. The difference is even greater in Spain, with $52 \%$ of migrants exiting unemployment compared to $31 \%$ of non-migrants. There is also evidence of far higher rates of job-to-job movement for migrants. In both countries, over one-third of all those in employment at $t-1$ who migrate are working for a new employer at $t$. Unsurprisingly, migration is associated with a higher rate of job hires.

Although these facts accord with the simple model which equates migration with job matches, is unsatisfactory in that it does not explain why migrants 
have a higher rate of job loss as well as job acquisition. In the UK nearly $9 \%$ of migrants who were employed at $t-1$ are unemployed at $t$, compared to only $3 \%$ of non-migrants. In Spain an even higher proportion of migrants lose their jobs, over 25\%. Similarly, our assumption that the unemployed only move region if they have a job to go to is challenged by the fact that a substantial number of migrants remain in unemployment (35\% in the UK, $40 \%$ in Spain).

There are at least two possible explanations which are consistent with our model. First, because we are measuring employment status over a discrete 12-month interval, it is possible that migrants find employment, change region and then lose their job. In the UK data we can examine this by looking at whether those who are unemployed at $t-1$ and $t$ actually left a job in the last 12 months. If they have, then this would suggest that they had a job in the intervening period. From this measure, we find that about $23 \%$ of migrants who are unemployed at $t$ and $t-1$ had a job in the intervening period. This obviously reduces the proportion of migrants who appear to move without finding a job match.

The second possible explanation for migrants failing to find a job match is that the migration occurs because a partner finds a job match. For example, a non-working woman may move region because their partner finds a job in a new region, but may themselves remain non-employed. In Table 7 we report labour market transitions for migrants split by the employment status of the individual's partner.

Table 7 shows that in both the UK and Spain the proportion of single migrants who remain unemployed is approximately the same as the overall proportion of migrants who remain unemployed ( $37 \%$ in the UK, $39 \%$ in Spain). Interestingly, however, there are noticeable differences in the transitions out of unemployment depending on partner's economic status. In the UK, by far the highest exit rates from unemployment $(67 \%)$ are among those who also have an employed partner. ${ }^{4}$ In Spain, in complete contrast, the highest exit rates (68\% and 56\%) are among those whose partners are inactive or those who are single.

Thus in Spain there is some evidence that migration is more closely associ-

\footnotetext{
${ }^{4}$ This is consistent with the work of Gregg, Hansen \& Wadsworth (1999) who show that work is more concentrated between households in the UK than other European countries.
} 


\begin{tabular}{|c|c|c|c|c|c|c|c|c|}
\hline \multicolumn{9}{|c|}{ (a) UK } \\
\hline & \multicolumn{4}{|c|}{ Partner employed } & \multicolumn{4}{|c|}{ Partner unemployed } \\
\hline & $J$ (same) & $J($ new) & $U$ & $N$ & $J$ (same) & $J$ (new) & $U$ & $N$ \\
\hline$J$ & 49.26 & 34.79 & 6.77 & 9.18 & 44.02 & 30.61 & 16.62 & 8.75 \\
\hline$U$ & & 66.88 & 17.83 & 15.29 & & 45.00 & 32.50 & 22.50 \\
\hline \multirow[t]{3}{*}{$N$} & & 29.86 & 8.27 & 61.87 & & 11.02 & 11.02 & 77.95 \\
\hline & \multicolumn{4}{|c|}{ Partner inactive } & \multicolumn{4}{|c|}{ No partner } \\
\hline & $J$ (same) & $J($ new) & $U$ & $N$ & $J$ (same) & $J$ (new) & $U$ & $N$ \\
\hline$J$ & 52.31 & 30.58 & 7.69 & 9.42 & 36.81 & 40.43 & 10.03 & 12.77 \\
\hline$U$ & & 34.17 & 47.50 & 18.33 & & 45.05 & 37.13 & 17.82 \\
\hline$N$ & & 14.74 & 4.17 & 81.09 & & 40.95 & 9.27 & 49.78 \\
\hline
\end{tabular}

(b) Spain

\begin{tabular}{|c|c|c|c|c|c|c|c|c|}
\hline & \multicolumn{4}{|c|}{ Partner employed } & \multicolumn{4}{|c|}{ Partner unemployed } \\
\hline & $J$ (same) & $J$ (new) & $U$ & $N$ & $J$ (same) & $J$ (new) & $U$ & $N$ \\
\hline$J$ & 38.72 & 26.38 & 22.55 & 12.34 & 41.90 & 29.52 & 26.67 & 1.90 \\
\hline$U$ & & 38.66 & 44.00 & 17.33 & & 33.33 & 62.50 & 4.17 \\
\hline \multirow[t]{3}{*}{$N$} & & 11.19 & 8.21 & 80.60 & & 16.67 & 16.67 & 66.67 \\
\hline & \multicolumn{4}{|c|}{ Partner inactive } & \multicolumn{4}{|c|}{ No partner } \\
\hline & $J$ (same) & $J$ (new) & $U$ & $N$ & $J$ (same) & $J$ (new) & $U$ & $N$ \\
\hline$J$ & 56.62 & 29.78 & 8.46 & 5.15 & 23.00 & 37.31 & 31.59 & 8.10 \\
\hline$U$ & & 67.86 & 25.00 & 7.14 & & 56.32 & 38.99 & 4.69 \\
\hline$N$ & & 7.35 & 5.88 & 86.76 & & 24.30 & 16.73 & 58.97 \\
\hline
\end{tabular}

Table 7: Employment transitions of migrants by partner's economic status

ated with job acquisition for those whose partners are not economically active, which is consistent with the model. However, in the UK job acquisition among migrants is actually higher for those whose partners are economically active. We should recognise therefore that although job acquisition is an important (perhaps the most important) determinant of migration, our simple model does not capture all the causes of migration.

\section{$5 \quad$ Econometric results}

We now turn to formal multivariate econometric modelling of the relationship between migration and unemployment exit rates, using estimates of Equations (3) and (4). Because we are using individual level data, we are able to control for possible differences in migration and unemployment transitions 
which occur because of differences in the characteristics of the samples or because of different effects of those characteristics.

Table 8 summarises the means and deviations of the explanatory variables we use in the econometric analysis. We are restricted to those variables which are available on a consistent basis both across countries and across the sample period, and we therefore concentrate on a limited number of key characteristics.

\begin{tabular}{lcccc}
\hline & \multicolumn{2}{c}{ UK } & \multicolumn{2}{c}{ Spain } \\
& Mean & S.D. & Mean & S.D. \\
& & & & \\
Employed at $t-1$ & 0.711 & $(0.453)$ & 0.478 & $(0.500)$ \\
Unemployed at $t-1$ & 0.061 & $(0.239)$ & 0.123 & $(0.329)$ \\
Inactive at $t-1$ & 0.228 & $(0.420)$ & 0.399 & $(0.490)$ \\
& & & & \\
Age 16-25 & 0.192 & $(0.394)$ & 0.268 & $(0.443)$ \\
Age 26-35 & 0.250 & $(0.433)$ & 0.220 & $(0.414)$ \\
Age 36-45 & 0.240 & $(0.427)$ & 0.200 & $(0.400)$ \\
Age 46-55 & 0.207 & $(0.405)$ & 0.178 & $(0.382)$ \\
Age 56-65 & 0.112 & $(0.315)$ & 0.135 & $(0.341)$ \\
& & & & \\
Male & 0.508 & $(0.500)$ & 0.519 & $(0.500)$ \\
Female & 0.492 & $(0.500)$ & 0.481 & $(0.500)$ \\
& & & & \\
No qualifications & 0.293 & $(0.455)$ & 0.555 & $(0.497)$ \\
16+ qualifications & 0.254 & $(0.435)$ & 0.184 & $(0.387)$ \\
18+ qualifications & 0.285 & $(0.452)$ & 0.157 & $(0.364)$ \\
Post-school qualifications & 0.063 & $(0.243)$ & 0.042 & $(0.201)$ \\
Higher education qualifications & 0.104 & $(0.305)$ & 0.062 & $(0.241)$ \\
& & & & \\
Relative unemployment rate & 1.045 & $(0.290)$ & 1.017 & $(0.299)$ \\
Relative vacancy rate & 1.002 & $(0.255)$ & 1.021 & $(0.558)$ \\
& & & & \\
Number of children aged 0-4 & 0.276 & $(0.607)$ & 0.211 & $(0.493)$ \\
Number of children aged $>5$ & 0.524 & $(0.876)$ & 0.684 & $(0.920)$ \\
& & & & \\
Partner employed at $t-1$ & 0.463 & $(0.499)$ & 0.306 & $(0.461)$ \\
Partner unemployed at $t-1$ & 0.026 & $(0.159)$ & 0.047 & $(0.211)$ \\
Partner inactive at $t-1$ & 0.129 & $(0.336)$ & 0.217 & $(0.412)$ \\
\hline
\end{tabular}

Table 8: Summary statistics

We include labour market state at $t-1$ because our model suggests that migration (and labour market transitions) depend on search intensity, which will tend to be higher for those who are unemployed and actively seeking work. It also seems likely that search intensity and migration propensities vary with age, possibly because the costs of moving increase with age. A key variable in 
our analysis is some measure of "skill", since it seems likely that both migration propensity and unemployment transitions will vary considerably across skill groups. Our measure of skill is based on qualifications received, rather than on occupation, because information on occupation is not necessarily available for individuals who are not currently employed.

The model suggests that variation in unemployment and vacancy rates across regions will affect both migration and unemployment transitions. In Equation (3), the probability of migration is positively affected by the relative unemployment and vacancy rates in the current region compared to all other regions. A high relative unemployment rate should increase out-migration, while a high relative vacancy rate should reduce out-migration.

The final set of variables are intended to capture differences in costs of migration. As noted in Section 2, migration propensity will vary with the costs of migration, which in turn will be a function of inter alia housing tenure and household structure. The data do not allow us to identify household tenure at $t-1$, and so the variables we focus on are based on household structure, namely whether the household has children of pre-school or school age, and the employment status of each individual's partner.

The Spanish sample has a considerably higher proportion reporting inactivity than the UK sample, a younger age structure and a higher proportion with no educational qualifications.

\subsection{Migration results}

Table 9 reports estimates of Equation (3) using the entire sample pooled across years and across employment status at $t-1 .^{5}$ We found that due to the very small numbers migrating, particularly in Spain, a pooled model was necessary to identify significant factors.

\footnotetext{
${ }^{5}$ Disaggregated estimates of (3) are available from the authors on request.
} 


\begin{tabular}{|c|c|c|c|c|c|c|}
\hline & Coeff. & $\begin{array}{c}\text { UK } \\
\text { Marginal } \\
\text { Effect }^{\mathrm{a}, \mathrm{b}}\end{array}$ & P-value & Coeff. & $\begin{array}{c}\text { Spain } \\
\text { Marginal } \\
\text { Effect }^{\mathrm{a}, \mathrm{b}}\end{array}$ & P-value \\
\hline Unemployed at $t-1$ & 0.1514 & 0.4380 & {$[0.000]$} & -0.0285 & -0.0142 & {$[0.166]$} \\
\hline Inactive at $t-1$ & 0.2928 & 0.8821 & {$[0.000]$} & 0.0362 & 0.0189 & {$[0.024]$} \\
\hline Age $26-35$ & -0.1498 & -0.3397 & {$[0.000]$} & 0.0839 & 0.0465 & {$[0.000]$} \\
\hline Age $36-45$ & -0.4034 & -0.7995 & {$[0.000]$} & -0.0999 & -0.0473 & {$[0.000]$} \\
\hline Age $46-55$ & -0.6438 & -1.0949 & {$[0.000]$} & -0.2601 & -0.1069 & {$[0.000]$} \\
\hline Age $56-65$ & -0.8009 & -1.0547 & {$[0.000]$} & -0.3377 & -0.1251 & {$[0.000]$} \\
\hline Female & -0.0128 & -0.0315 & {$[0.196]$} & -0.0802 & -0.0413 & {$[0.000]$} \\
\hline $16+$ qualifications & 0.0754 & 0.1947 & {$[0.000]$} & 0.0312 & 0.0166 & [0.097] \\
\hline $18+$ qualifications & 0.2863 & 0.8271 & {$[0.000]$} & 0.0542 & 0.0296 & {$[0.004]$} \\
\hline Post-school qualifications & 0.3775 & 1.3865 & {$[0.000]$} & 0.2238 & 0.1577 & {$[0.000]$} \\
\hline Higher education qualifications & 0.6657 & 3.1396 & {$[0.000]$} & 0.2064 & 0.1403 & {$[0.000]$} \\
\hline Number of children aged $0-4$ & -0.0707 & -0.1746 & {$[0.000]$} & 0.0912 & 0.0471 & {$[0.000]$} \\
\hline Number of children aged $>5$ & -0.1062 & -0.2622 & {$[0.000]$} & -0.0448 & -0.0231 & {$[0.000]$} \\
\hline Partner employed at $t-1$ & -0.0901 & -0.2209 & {$[0.000]$} & -0.2974 & -0.1331 & [0.000] \\
\hline Partner unemployed at $t-1$ & 0.0751 & 0.2016 & {$[0.058]$} & -0.0803 & -0.0373 & {$[0.055]$} \\
\hline Partner inactive at $t-1$ & 0.0833 & 0.2213 & {$[0.000]$} & -0.1623 & -0.0737 & {$[0.000]$} \\
\hline Female $\times$ Partner emp & 0.0242 & 0.0606 & {$[0.125]$} & 0.1145 & 0.0652 & {$[0.002]$} \\
\hline Female $\times$ Partner unemp. & -0.0464 & -0.1086 & {$[0.344]$} & 0.0448 & 0.0247 & {$[0.474]$} \\
\hline Female $\times$ Partner inact. & -0.0247 & -0.0593 & {$[0.405]$} & 0.0794 & 0.0458 & {$[0.156]$} \\
\hline Relative unemployment rate & -0.1066 & -0.2630 & {$[0.003]$} & -0.2997 & -0.1547 & {$[0.002]$} \\
\hline Relative vacancy rate & -0.0521 & -0.1286 & {$[0.062]$} & -0.0070 & -0.0036 & {$[0.750]$} \\
\hline Constant & -1.8208 & & {$[0.000]$} & -2.4847 & & {$[0.000]$} \\
\hline Time dummies & \multicolumn{3}{|c|}{ Yes } & \multicolumn{3}{|c|}{ Yes } \\
\hline Region dummies & \multicolumn{3}{|c|}{ Yes } & \multicolumn{3}{|c|}{ Yes } \\
\hline $\operatorname{Pr}\left(m_{i t}=1\right) \times 100$ & \multicolumn{3}{|c|}{1.463} & \multicolumn{3}{|c|}{0.245} \\
\hline & \multicolumn{3}{|c|}{963321} & \multicolumn{3}{|c|}{1151307} \\
\hline $\log L$ & \multicolumn{3}{|c|}{-66588.874} & \multicolumn{3}{|c|}{-18421.879} \\
\hline
\end{tabular}

Table 9: Migration Probit results: pooled model

The effects of most personal characteristics are qualitatively similar for both countries. Migration propensity is decreasing strongly in age, although in Spain the most mobile group are those age 26-35, rather than those aged 16-25 as in the UK. This may be a result of young people tending to remain in the parental home for longer in Spain. Females are less mobile than males in both countries, although the effect is significant only in Spain. In both countries migration increases significantly with skill-level. In the UK this effect is large: the overall average probability of migration is $1.46 \%$, while for those with "Post-school qualifications" it is $2.85 \%(1.46+1.39)$, and for those with higher education 
qualifications it is $4.6 \%(1.46+3.16)$. In Spain there is also an increase in mobility with education, but each group is far less likely to migrate than its counterpart in the UK. Spanish workers with higher education qualifications have a migration probability of only $0.39 \%(0.25+0.14)$, for example. So we can say that the large differences in migration between the two countries are almost certainly not due to differences in the age and skill-level of the population.

The next set of coefficient estimates are those intended to measure the costs of migration. In the UK, as expected, individuals living in households with children are significantly less mobile, and this effect is large for households with school-age children. In Spain, the negative effect is only apparent for school-age children. In both countries individuals with employed partners are significantly less likely to move, as predicted, while in the UK those with unemployed or inactive partners are actually more likely to move than the base group (those without partners). In Spain, the most mobile are those without a partner in the household.

The most surprising results from Table 9 are those on the relative unemployment rates. Our model unambiguously predicts that individuals living in regions with relatively high unemployment rates or relatively low vacancy rates should receive a greater proportion of job offers from other regions, and should therefore be more likely to migrate. The coefficient on relative vacancy rates is therefore correctly signed, although insignificantly different from zero in Spain. However, our results suggest that individuals in high unemployment regions are actually significantly less likely to migrate. We have experimented with various specifications to see how robust this result is, and it does appear consistent. Note that our specification includes region and time dummies, and so this effect is not caused by omitted regional fixed-effects. That is, it is not simply the case that migration propensity is lower in high unemployment regions. We are puzzled by this result, but it is not unusual in the large literature measuring migration. Pissarides \& Wadsworth (1989) for the UK and Antolin \& Bover (1997) for Spain, estimate similar migration equations using the same data, and both find similar results. ${ }^{6}$

As noted earlier, our definitions of regions are crude and do not correspond closely to the theoretical idea of a region being an area within which one can

\footnotetext{
${ }^{6}$ See also Greenwood (1997).
} 
change jobs without changing residence. It might be suggested that more disaggregated unemployment rates would give more satisfactory results. As noted both by Pissarides \& Wadsworth and Antolin \& Bover, these results also highlight that personal characteristics are more important in explaining migration decisions than regional demand conditions.

\subsection{Unemployment transition results}

From our estimates of Equation (3) we can calculate an estimate of the migration propensity for each individual, denoted $\hat{\mathbf{y}}_{1}^{*}$. We would expect that individuals with higher migration propensities will have higher exit rates from unemployment. Table 10 reports estimates of Equation (4). In order to identify the effect of migration propensity on unemployment exit rates we require that some variables affect the costs of migration without (directly) affecting the offer arrival rate. We have therefore excluded the variables measuring the number of children from estimates of Equation (4).

As with the migration estimates, the coefficients on the age and qualifications variables are as expected and similar across countries. Younger workers and workers with higher qualifications have higher exit rates from unemployment. It is interesting to note that in the UK the difference between those with no qualifications and all other qualification groups is much greater than in Spain, suggesting a greater penalty in the UK for being in the bottom skill group. Females in the UK have significantly higher exit rates, while females in Spain have significantly lower exit rates. As noted in Section 4, in the UK those with employed partners have much higher exit rates, although this effect is mitigated somewhat for women. 


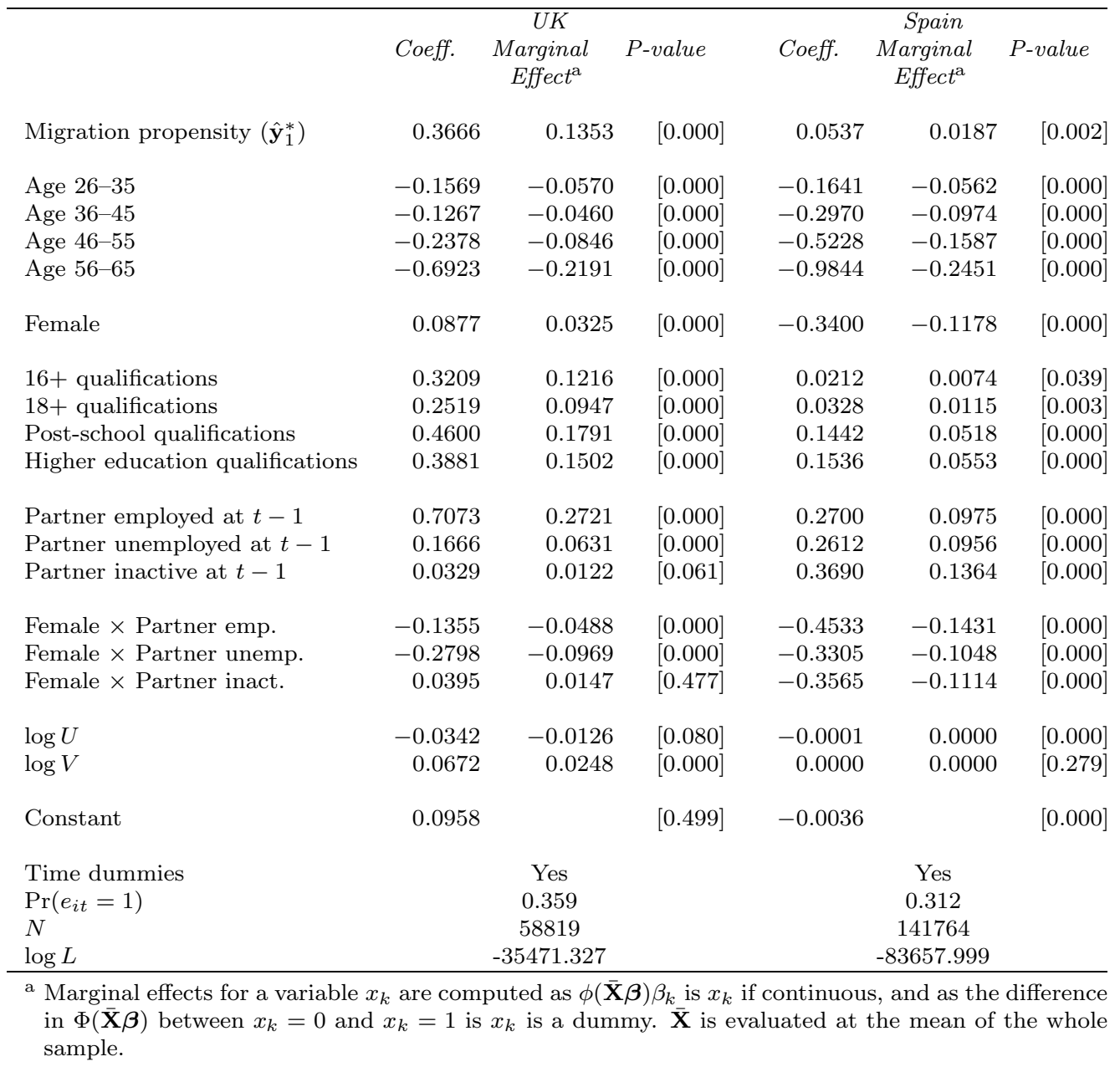

Table 10: Unemployment transition Probit results

The coefficient on $\hat{\mathbf{y}}_{1}^{*}$ is significant and positive in both countries. As expected, individuals with higher predicted propensities to migrate have higher unemployment transitions. Note that this is not due to the fact that those with high $m^{*}$ tend to be younger and more qualified, since we have also included these variables in the second stage regression. Significantly, the marginal effect of $\hat{\mathbf{y}}_{1}^{*}$ is much larger in the UK than in Spain. Evaluated at the means of the data, the elasticity of the probability of exiting unemployment with respect to the migration propensity is 0.932 for the UK and only 0.175 for Spain. ${ }^{7}$ This suggests that the benefits of greater mobility are far higher in the UK than in Spain. In the context of the model, the increased job offer arrival rate for the mobile in Spain is relatively small.

\footnotetext{
${ }^{7}$ The elasticity is given by $\frac{\partial \operatorname{Pr}(j=1)}{\partial \mathbf{y}_{1}^{*}} \frac{\mathbf{y}_{1}^{*}}{\operatorname{Pr}(j=1)}$.
} 


\subsection{Migration and skill groups}

As noted earlier, Gregg et al. (2001) argue that in the UK the labour market is far more integrated for skilled than for unskilled workers, because vacancies for unskilled jobs tend to be only advertised locally. One implication of this hypothesis is that individuals searching for unskilled vacancies who are willing to move region receive the same number of job offers as a job-seeker who is unwilling to move region. But for job-seekers searching for skilled vacancies the willingness to move region should be more important. Thus an individual's migration propensity should have less impact on their probability of exiting unemployment for unskilled workers. In Table 11 we report estimates of Equation (4) separately for each educational qualification group.

\begin{tabular}{|c|c|c|c|c|c|c|}
\hline & \multicolumn{2}{|c|}{$\overline{U K}$} & \multicolumn{4}{|c|}{ Spain } \\
\hline & Coeff. & $\begin{array}{c}\text { Marginal } \\
\text { Effect }^{\mathrm{a}}\end{array}$ & $P$-value & Coeff. & $\begin{array}{c}\text { Marginal } \\
\text { Effect }^{\mathrm{a}}\end{array}$ & $P$-value \\
\hline Coefficient on $\hat{\mathbf{y}}_{1}^{*}$ & & & & & & \\
\hline No qualifications & 0.414 & 0.130 & {$[0.000]$} & -0.1085 & -0.0332 & [0.105] \\
\hline $16+$ quals. & 0.194 & 0.077 & {$[0.002]$} & -0.0749 & -0.0255 & {$[0.018]$} \\
\hline $18+$ quals. & 0.422 & 0.162 & {$[0.000]$} & 0.1137 & 0.0402 & {$[0.000]$} \\
\hline Post-school quals. & 0.323 & 0.123 & [0.103] & 0.2614 & 0.0955 & [0.000] \\
\hline Higher education quals. & 0.062 & 0.025 & {$[0.692]$} & 0.0271 & 0.0098 & [0.631] \\
\hline
\end{tabular}

${ }^{a}$ Regression includes all the variables reported in Table 10 apart from the qualification dummies.

Table 11: Effect of $\hat{\mathbf{y}}_{1}^{*}$ on unemployment transition by skill group

In the UK we find no support for the hypothesis that the benefits of being regionally mobile are greater for the more educated. In fact, the coefficient on $\hat{\mathbf{y}}_{1}^{*}$ is larger and more significant for the less-highly educated groups. In Spain, in contrast, there does appear to be a significantly greater effect of migration propensity on higher skill groups, with the exception of the top group. However, the marginal effect on all education groups is smaller than the corresponding coefficient for the UK. 


\section{Conclusions}

In this paper we have provided comparable descriptive evidence and econometric analysis on the relationship between the probability of migration and the probability of exiting unemployment. We have done this for two countries which have experienced very different unemployment rates and levels of migration. In order to try and disentangle the relationship between migration and job acquisition, we use a simple model of job search which assumes that migration is the result of accepting a job offer from another region. In order to identify the model, we assume that individuals vary in their willingness to search for, or accept, jobs in other regions.

It would seem that Spain is effectively an economy with almost no migration. While rates in the UK are higher, they are still low in comparison with other OECD economies. We find in both countries that individuals' propensities to migrate are similarly correlated with individual and household characteristics, but are at best only weakly affected by the economic conditions of the region in which they live. Indeed, there is evidence, consistent with previous work, that migration is actually negatively related to the relative regional unemployment rate. None of the explanatory variables used to estimate Equation (3) can explain why migration is so much lower (and falling) in Spain, and this is an issue which deserves further analysis. Various authors have suggested that migration in Spain may be low and unresponsive to local demand conditions partly because of the mechanisms for claiming unemployment benefit, for example.

The key result from our analysis of unemployment transitions is that the benefit of increased migration propensity is rather lower in Spain that in the UK. A job-seeker in Spain who is prepared to move regions does have increased unemployment exit rates, but the effect is smaller than in the UK. Note that this result does not simply reflect the fact that migration propensities are so much lower in Spain than in the UK. It is perfectly consistent with the model that job-seekers in Spain who are more willing to migrate should gain as much as mobile job-seekers in the UK.

One possible explanation is that the matching process itself is less efficient in Spain, perhaps because information about vacancies at a national level is less 
complete in Spain than in the UK, so that those who are willing to move region gain a relatively smaller increase in job offers. More institutional detail would be required to test this hypothesis. ${ }^{8}$

A second explanation is suggested by Antolin \& Bover, who argue that one reason migration is so unusual in Spain is because migrants who are seeking work are placed at the back of "job queues" in their new region. Although this is not strictly consistent with our model (since migrants should only move once they have found a job) this might provide another reason why the more mobile in Spain are less successful at finding work.

To what extent does the lack of migration in Spain lead to lower unemployment exit rates and higher equilibrium unemployment? In fact, because the estimated elasticity of $\hat{\mathbf{y}}_{1}^{*}$ with respect to $\operatorname{Pr}(j=1)$ is relatively low in Spain, the effect is quite small. An increase in migration propensity in Spain would have a smaller impact on unemployment exit rates than would an equal and opposite decline in migration propensity in the UK.

A more general finding, which we feel is important, is the extent to which labour (even highly skilled labour) is relatively immobile between regions. For whatever reason, the costs of relocation are clearly high even when regions are hit by negative demand shocks. This result is of course well known, as illustrated by the continuing discussion of regional disparities in unemployment and wages. But perhaps it is worth reiterating that the reallocation of employment across regions caused by industrial restructuring is likely to be costly to workers.

\section{References}

Antolin, P. \& Bover, O. (1997), "Regional migration in Spain: the effect of personal characteristics and of unemployment, wage and house price differentials using pooled cross-sections", Oxford Bulletin of Economics and Statistics 59, 215-235.

\footnotetext{
${ }^{8}$ In fact, Employment Offices in Spain are linked nationally, and so in principle information on all publicly advertised vacancies are available nationally (Antolin \& Bover 1997).
} 
Bentolila, S. (1997), "Sticky labour in Spanish regions", European Economic Review 41, 591-598.

Bentolila, S. \& Blanchard, O. (1990), "Spanish unemployment", Economic Policy 10, 233-265.

Blanchard, O. \& Wolfers, J. (2000), "The role of shocks and institutions in the rise of European unemployment", The Economic Journal 110, C1-C33.

Böheim, R. \& Taylor, M. (1999), "Residential mobility, housing tenure and the labour market in Britain", Mimeo, Institute for Social and Economic Research, University of Essex.

Bover, O. \& Arellano, M. (2001), "Learning about migration from migrants: using complementary datasets to model intra-regional migration in Spain", CEPR working paper 2746.

Bover, O., Barćia-Perea, P. \& Portugal, P. (2000), "Labour market outliers: lessons from Portugal and Spain", Economic Policy 15, 379-428.

Cameron, G. \& Muellbauer, J. (1998), "The housing market and regional commuting and migration choices", Scottish Journal of Political Economy 45, 420-446.

Gardner, J., Pierre, G. \& Oswald, A. (2001), "Moving for job reasons", Mimeo, Department of Economics, University of Warwick.

Greene, W. (2000), Econometric Analysis, 4th edn, Prentice Hall.

Greenwood, M. (1997), "Internal migration in developed countries", in M. Rosenzweig \& O. Stark, eds, Handbook of population economics and family economics, Vol. 1B, Elsevier.

Gregg, P., Hansen, K. \& Wadsworth, J. (1999), "The rise of the workless household", in P. Gregg \& P. Wadsworth, eds, The State of Working Britain, Manchester Uiversity Press, chapter 5, pp. 75-89.

Gregg, P., Machin, S. \& Manning, A. (2001), "Mobility and joblessness", Paper presented at NBER conference on "Seeking a Premier League Economy".

Henley, A. (1998), "Residential mobility, housing equity and the labour market", The Economic Journal 108, 414-427.

Hughes, G. \& McCormick, B. (1981), "Do council house policies reduce migration between regions?", The Economic Journal 91, 919-937.

Instituto Nacional de Estadística (2002), "La Encuesta de Población Activa User Guide". 
Jackman, R. \& Savouri, S. (1992), "Regional migration in Britain: an analysis of gross flows using NHS central register data", The Economic Journal 102, 1433-1450.

Layard, R., Nickell, S. \& Jackman, R. (1991), Unemployment: Macroeconomic Performance and the Labour Market, Oxford: Oxford University Press.

Mortensen, D. (1986), "Job search and labor market analysis", in O. Ashenfelter \& R. Layard, eds, Handbook of Labor Economics, Vol. 2, Amsterdam: North-Holland, pp. 849-919.

Nickell, S. (1997), "Unemployment and labor market rigidities: Europe versus North America", Journal of Economic Perspectives 11, 55-74.

Office for National Statistics (2002), "Labour Force Survey User Guide".

Oswald, A. (1996), "A conjecture on the explanation for high unemployment in the industrialized nations: Part I", Mimeo, Department of Economics, University of Warwick.

Pissarides, C. (2000), Equilibrium Unemployment Theory, The MIT Press.

Pissarides, C. \& Wadsworth, J. (1989), "Unemployment and the inter-regional mobility of labour", The Economic Journal 99, 739-755.

Sjaastad, L. (1962), "The costs and returns of human migration", Journal of Political Economy 70(5), 80-93.

Wooldridge, J. (2002), The econometric analysis of cross section and panel data, MIT Press. 